\title{
Dentin dysplasia type II
}

\author{
INSERM
}

\section{Source}

INSERM. (1999). Orphanet: an online rare disease and orphan drug data base. Dentin dysplasia type II. ORPHA:99791

Dentin dysplasia type II (DD-II) is a rare mild form of dentin dysplasia (DD, see this term) characterized by normal tooth roots but abnormal primary dentition. 